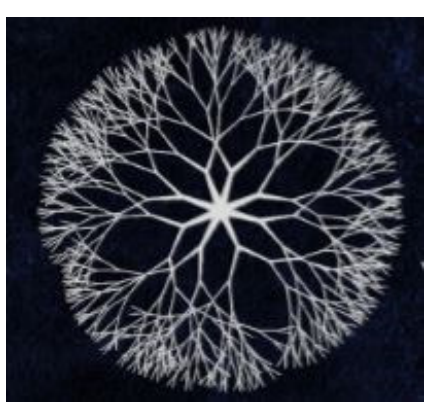

\title{
A psicocirurgia em instituições da ordem pública e privada: difusão prático-científica da lobotomia pré-frontal
}

\author{
Camilie Cardoso \\ Graduada em História - FFLCH-USP \\ Coordenadora em Projetos de Memória do Memória \& Identidade \\ camilie.cada@gmail.com
}

Recebido em 20/07/2017. Aprovado em 10/08/2017.

Como citar este artigo: Cardoso, C. "A psicocirurgia em instituições da ordem pública e privada: difusão práticocientífica da lobotomia pré-frontal”. Khronos, Revista de História da Ciência, nº 4, pp. 116 - 131. 2017. Disponível em $<$ http://revistas.usp.br/khronos >. Acesso em dd/mm/aaaa.

Resumo: Visando a compreender as aplicações da lobotomia pré-frontal em hospitais psiquiátricos integrados às esferas pública e privada, este trabalho é centrado na análise de artigos publicados por Barretto (1944, 1945) e Longo et. al (1949). Caracterizada como uma psicocirurgia de baixo custo, a técnica teve seu emprego justificado pela rápida supressão de sintomas etiologicamente associados ao desvio dos padrões que fundamentam a caracterização do doente como tal. Partindo desse cenário, pretendo investigar a forma como essa lógica normalizante está vinculada a afirmação - e constante reafirmação - de papéis sociais que amalgamam-se à perspectiva histórica e cultural dos autores analisados.

Palavras-chave: Lobotomia, Psicocirurgia, Psiquiatria.

\section{Psychosurgery in institutions of public and private order: practical-scientific diffusion of the prefrontal lobotomy}

\begin{abstract}
In order to understand the applications of pre-frontal lobotomy in psychiatric hospitals integrated into the public and private spheres, this work is focused on the analysis of articles published by Barretto (1944, 1945) e Longo et al. (1949). Characterized as a low cost surgery, the procedure was justified by the quick suppression of symptoms aetiologically associated with the deviation of the patterns that underlie the characterization of the unhealthy as such. With this scenario in mind, I intend to investigate how that normalizing logic is linked to the affirmation (and reaffirmation) of social roles that are merged to the historical and cultural perspective exposed by those authors.
\end{abstract}

Keywords: Lobotomy, Psychosurgery, Psychiatry. 


\section{A lobotomia pré-frontal}

Fundamentado por artigos de difusão publicados nos Arquivos de Neuro-Psiquiatria entre os anos de 1944 e 1949, este estudo é centrado na aplicação da lobotomia pré-frontal como tratamento psicocirúrgico em hospitais psiquiátricos paulistas integrados à ordem pública e privada, recorte estabelecido de forma a compreender os aspectos socioeconômicos que tangem o emprego da técnica nesses diferentes cenários. A fim de articular os objetivos, informações e resultados aduzidos com as especificidades dos espaços em que as intervenções foram conduzidas, serão utilizadas como fontes duas publicações de Antonio Carlos Barreto ${ }^{1}$, que à época atuou como cirurgião no Hospital Juqueri, localizado em Franco da Rocha, na região metropolitana de São Paulo. A passagem seguinte se voltará para o artigo publicado em 1949 por Paulino W. Longo, A. Mattos Pimenta e Joy Arruda com base nos resultados clínicos obtidos pelo Serviço de Neuro-Psiquiatria do Instituto Paulista, uma instituição privada.

Considerado como responsável pelo advento da lobotomia, a primeira indicação de Egas Moniz ao Prêmio Nobel de Medicina ocorreu em 1928, concedida em virtude de estudos voltados para a angiografia cerebral. Esse trabalho, contudo, não impactou a comunidade científica de forma tão significativa quanto a sua dedicação à leucotomia ao longo da década de $1930^{2}$. Pautado pelo conceito de plasticidade sináptica e pelas estruturas nervosas descritas por Santiago Ramón y Cajal em 1888, que posteriormente se estabeleceram de forma paradigmática ${ }^{3}$, Moniz concluiu que os transtornos mentais eram originados por desordens sinápticas. Responsável pelo predomínio de ideias obsessivas em pessoas consideradas como mentalmente doentes, tal desequilíbrio leva à absorção do foco originalmente destinado a outras atividades mentais ${ }^{4}$. Em 1935, o neurofisiologista John Fulton apresentou uma pesquisa com os resultados de uma técnica experimental, a qual consistia na realização de secções bilaterais no córtex pré-frontal de dois chimpanzés que, anteriormente, apresentavam respostas agressivas a situações de frustração. O resultado do método consistiu sumamente na obtenção do esvaziamento da expressão emocional, o que impulsionou Egas Moniz, que estava presente nessa mesma conferência, a aplicar a lobotomia pré-frontal como um tratamento voltado a indivíduos diagnosticados com esquizofrenia e depressão. O neurologista acreditava que o corte das fibras conectivas dos neurônios se legitimava pelo objetivo de alterar a dinâmica das instalações sinápticas, assim como o próprio trajeto percorrido pelos estímulos em questão, o que alteraria os pensamentos disfuncionais e direcionaria para outros canais ${ }^{5}$. Em 1949, este trabalho rendeu ao seu idealizador o Prêmio Nobel da Medicina ${ }^{6}$.

${ }^{1}$ BARRETTO, Antonio Carlos. Leucotomia pré-frontal a Egas Moniz: Resultados imediatos e tardios em 100 casos. Arquivos de Neuro-Psiquiatria, São Paulo, v. 2, n. 3, 1944; BARRETTO, Antonio Carlos. Lobotomia pré-frontal. Arquivos de Neuro-Psiquiatria, São Paulo, v. 3, n. 4, 1945.

2 GROSS, Dominik; SCHÄFER, Gereon. Egas Moniz (1874-1955) and the "invention” of modern psychosurgery: a historical and ethical reanalysis under special consideration of Portuguese original sources. Neurosurg Focus, v. 30, n. 2, 2011, p. 1.

${ }^{3}$ SEGURA, Luis Miguel García. Ramón y Cajal y la neurociencia del siglo XXI. Jano Extra, n. 1583, 2005, p. 17.

${ }^{4}$ GROSS, 2011, op. cit., p. 1.

${ }^{5}$ MONIZ, Egas. Die präfrontale Leukotomie. Archiv für Psychiatrie, v. 181, 1949, pp. 591-602.

${ }^{6}$ BYARD, Roger W. Frontal lobotomy. Forensic Science, Medicine, and Pathology, Nova Iorque, v. 13, n. 2, 2017, p. 3. 
A disseminação da técnica, por sua vez, é usualmente atribuída ao trabalho de Walter Freeman e James Watts ${ }^{7}$. Freeman e Watts aprimoraram o processo por meio de iniciativas como o desenvolvimento de novos métodos cirúrgicos, os quais possibilitariam ampliar a abrangência do tratamento para pacientes diagnosticados com esquizofrenia e outras condições psicopatológicas; e a criação de lobotomias com diferentes níveis de afecção, da técnica transorbitária e de um procedimento que podia ser conduzido por qualquer médico no período de 15 a 20 minutos ${ }^{8}$. Em suma, a psicocirurgia consiste em interromper as fibras conectivas entre as células da zona pré-frontal e demais regiões por meio da secção da matéria branca cerebral ${ }^{9}$, processo no qual é introduzido um leucótomo ${ }^{10}$ a uma profundidade de 4.5 centímetros na direção anterolateral. $\mathrm{O}$ instrumento é direcionado de forma a promover um corte de 1 centímetro de diâmetro na matéria branca e, posteriormente, a lâmina é retraída a fim de seccionar um segundo núcleo, a 3.5 centímetros, e um terceiro, a 2.5 centímetros da superfície cerebral. Após esta etapa, o leucótomo é retirado e reinserido no local em que foi realizada a primeira secção, a fim de promover um novo corte na distância de 2 centímetros do cérebro ${ }^{11}$. Para o desenvolvedor do método, o propósito da lobotomia pode parecer muito audacioso, mas pode-se afirmar que essas cirurgias não são prejudiciais ao paciente ${ }^{12}$. Freeman e Watts, por sua vez, consideram que não se trata de um procedimento doloroso ou mesmo drástico - contudo, os mesmos autores reconhecem a provável decorrência do efeito diásquise após o rompimento abrupto de um número considerável de axônios e colaterais, o que impediria a percepção dos efeitos imediatos da intervenção ${ }^{13}$.

Os objetivos descritos pelos autores analisados convergem para o mesmo ponto. Justificando os quadros nosológicos de melancolia, hipocondria e paranoia por uma perspectiva fisiológica, Egas Moniz acredita que, apesar de os cilindro-eixos não apresentarem alterações anatômicas, as múltiplas ligações dos corpos celulares, "muito variáveis nas pessoas normais, poderão provocar arranjos mais ou menos fixos, que estarão em relação com as ideias persistentes e os delírios de certos estados psíquicos mórbidos"14, o que poderia ser atenuado ou solucionado pelo tratamento com a lobotomia pré-frontal. Walter Freeman e James Watts reconhecem a intervenção como um método passível de conter ou sanar sintomas como a inércia, falta de ambição, dificuldade de percepção das consequências ${ }^{15}$, perda da autoconsciência, indiferença

7 BARRETTO, 1945, op. cit., p. 420.

${ }^{8}$ BYARD, 2017, op. cit., p. 3.

${ }^{9}$ MONIZ, Egas. Prefrontal leucotomy in the treatment of mental disorders. American Journal of Psychiatry, v. 93, n. 6, 1937, p. 1379.

10 Descrito por Barretto, o aparelho idealizado por Egas Moniz é "constituído de uma cânula de metal de $11 \mathrm{cms}$. De comprimento, por $2 \mathrm{~mm}$. de diâmetro, dentro do qual se adapta outra peça móvel. Em uma das extremidades há uma fenda longitudinal de $1 \mathrm{~cm}$. de comprimento, que dará passagem a uma alça de fio de aço com meio centímetro de raio. Com movimentos adequados esta alça é exteriorizada ou recolhida" (BARRETTO, 1944, op. cit., p. 249).

11 MONIZ, Egas. Prefrontal leucotomy in the treatment of mental disorders. American Journal of Psycbiatry, v. 93, n. 6, 1937, p. 1380.

12 Idem, p. 1379.

13 FREEMAN, Walter; WATTS, James W. An interpretation of the functions of the frontal lobe: based upon observations in forty-eight cases of prefrontal lobotomy. Yale Journal of Biology and Medicine, v. 11, n. 5,1939 , p. 529.

${ }^{14}$ MONIZ, Egas. Tentatives opératoires dans le traitement de certaines psychoses. Paris: Masson et Cie., Paris, 1936 apud BARRETTO, 1944, op. cit., pp. 248-249.

15 Recorrendo a um evento ocorrido com um dos pacientes analisados, os autores relacionam a suposta dificuldade de estabelecer um pensamento consecutivo com uma percepção temporal arraigada de diacronia. "Just as the post-rolandic cortex is concerned with the past, the pre-rolandic cortex is concerned with the future. Aside from certain small areas that are concerned with the direct execution of muscular movements and the regulation of visceral function, the rest of the frontal cortex is, according to our hypothesis, concerned with the projection of the whole individual into the future. With the intact brain the individual is able to foresee, to see before, to forecast the results of certain activities that he is to 
quanto à opinião alheia, satisfação com performances de baixa qualidade, euforia, evasão, blefe, loquacidade, moria, agressividade, estado provocativo, indecência, desatenção e dificuldade de julgamento ${ }^{16}$. Em consonância com essas propostas, Barretto manifesta o intento de suprimir o sofrimento de ansiosos e melancólicos, atenuar a agitação psicomotora e certos complexos psíquicos, de forma a diminuir o número de doentes crônicos em hospitais psiquiátricos ${ }^{17}$. Paulino W. Longo, Mattos Pimenta e Joy Arruda acreditam na eficácia desse tratamento em "casos de início súbito consequente a alguma causa física ou psicológica, e que apresentam plasticidade na produção de sintomas tal como produtividade delirante, certo grau de tendência cíclica, uma ilhota de personalidade íntegra preservada no desastre psicótico"18.

Com o passar dos anos, a percepção dos resultados negativos dos procedimentos ${ }^{19}$ aumentava. Via-se que os índices de remissão eram baixos; que a maioria dos que haviam sido submetidos à intervenção permaneciam hospitalizados ou mantinham-se em casa em estado de dependência e ociosidade. Em diferentes instituições, a taxa de mortalidade associada à lobotomia era de 4 a 17\%; nos demais casos relatados, 15\% dos pacientes apresentaram epilepsia pósprocedural e mais de $60 \%$ desenvolveram mudanças problemáticas de personalidade ${ }^{20}$.

Conduzido no tribunal internacional formado em Nuremberg (1946), o debate sobre a necessidade de uma vigilância em âmbito global para impedir a decorrência de crimes contra a humanidade como os observados na Segunda Guerra Mundial, quando uma série de abusos foram cometidos "em nome de um suposto conhecimento científico"21, também contemplou discussões sobre os padrões éticos para pesquisas com seres humanos, levando a elaboração do Código de Nuremberg. No documento era firmada a importância do consentimento voluntário dos indivíduos submetidos a experimentos, que deveriam "exercer o livre direito de escolha sem qualquer intervenção de elementos de força" 22 , com o pleno conhecimento da natureza, duração, propósito, inconveniências e riscos aos quais estariam sujeitos ${ }^{23}$; da mesma forma, definia-se que não se deveria "ser conduzido qualquer experimento quando existirem razões para acreditar que

initiate in the future. And he can visualize what effect those actions will have upon himself and upon his environment. One patient expressed this concept almost directly. He was the man who slapped his nurses and pulled the fire alarm. "Now that I have done it," he said, "I can see it was not the thing to do, but beforehand I couldn't say whether or not it would be all right." A patient with intact frontal lobes can presumably define the goal toward which he is working, and estimate more or less dearly the nearness with which he approaches it. By projecting himself into the future in his "mind's eye" he is calling upon his cortical mechanisms to synthesize past experience as a guide, and upon his emotional mechanisms for driving force, the search for satisfaction, and the avoidance of distress. Once the goal is set he is further calling upon his cortical mechanisms to assemble the various parts of the problem and to select the proper course among the many alternatives that present themselves to him at the completion of each separate step. Corollary follows theorem in logical anticipation, and total behavior is modified in response to changed conditions. Satisfaction or dissatisfaction depends upon the recognition of the nearness that actuality approaches to the ideal that he has foreseen" (FREEMAN, 1939, op. cit., pp. 536-537).

${ }^{16}$ FREEMAN, Walter; WATTS, James W., 1939, op. cit., p. 537.

${ }_{17}$ BARRETTO, 1944, op. cit., p. 251.

${ }^{18}$ LONGO, Paulino W.; PIMENTA, A. Mattos; ARRUDA, Joy. Lobotomia pré-frontal: resultados clínicos em hospital privado. Arquivos de Neuro-Psiquiatria, São Paulo, v. 7, n. 2, 1949, pp. 127-128.

19 Também se denotava o impacto de problemas técnicos como "the use of freehand ablative techniques by individuals not necessarily trained in surgery which sometimes led to significant and disabling adverse outcomes" (BYARD, 2017, op. cit., p. 4).

${ }^{20}$ BYARD, 2017, op. cit., p. 4. Na referida passagem o autor também se refere a um estudo sobre o aumento do número de homicídios perpetrados por pacientes lobotomizados, mas considera que os resultados não são tão claros devido ao material diminuto disponível sobre o assunto.

${ }^{21}$ MASIERO, André Luis. A lobotomia e a leucotomia nos manicômios brasileiros. História, Ciências, Saúde Manguinhos, v. 10, n. 2, 2003, p. 569.

22 NUREMBERG, Código de. Tribunal Internacional de Nuremberg, 1947. Disponível em:

$<$ https://www.ufrgs.br/bioetica/nuremcod.htm $>$.

${ }^{23}$ Idem. 
pode ocorrer morte ou invalidez"24. A publicação do documento em 1947 não impediu, contudo, que as psicocirurgias deixassem de ser realizadas em instituições psiquiátricas brasileiras, onde a prática permaneceu ativa ao menos até o ano de 195625. Como aludido por André Masiero,

Mesmo com as mortes, com as sequelas deixadas ou os grandes riscos a que estavam sujeitos os doentes mentais lobotomizados, nenhum dos envolvidos nesta prática preocupou-se com a discussão ética destes procedimentos, limitando-se a taxar de pessimistas (Longo et al., 1956) os poucos opositores. A crítica do procedimento viria depois do seu abandono. Muitas outras conferências internacionais pretenderam lançar fundamentos éticos para pesquisa com seres humanos, mas, segundo Hossne et al. (1999), situações duvidosas ou abusivas continuaram e continuam ocorrendo na pesquisa médica mundial, o que aponta para a necessidade de uma constante vigilância e reflexão sobre a ética dos procedimentos médicos e científicos. ${ }^{26}$

Remontar o cenário em que grande parcela da comunidade psiquiátrica brasileira se manteve fechada para os debates sobre a ética na condução de tratamentos experimentais como a lobotomia pré-frontal remete à intrínseca relação da Psiquiatria com a Medicina Social. Expressa na literatura ou nas mobilizações construídas pelos agentes integrados à ordem dos manicômios, a problematização da lógica a qual estão integradas - e a que reproduzem - levou ao reconhecimento dessas instituições como emblemas "das relações de violência, segregação, massificação e discriminação social" 27 . O avanço dialógico com a saúde coletiva ${ }^{28}$, portanto, não anula a importância da problematização das percepções teóricas ou mecanismos utilizados na prática psiquiátricas ao longo da história; afinal, o caráter social é imanente às questões correlatas à saúde mental.

\section{A lobotomia no âmbito de uma instituição pública: Hospital do Juqueri}

Barretto enuncia sua publicação Leucotomia pré-frontal a Egas Moniz: Técnica: Resultados imediatos e tardios em 100 casos especificando-a como uma divulgação das "vantagens terapêuticas"29 da leucotomia, na qual pretende esclarecer sobre a "simplicidade e inocuidade da intervenção" 30. Publicado no ano seguinte, o artigo intitulado Lobotomia pré-frontal inicia com um breve panorama

\footnotetext{
${ }^{24}$ Idem.

${ }^{25}$ LONGO, Paulino W.; ARRUDA, Joy; FIGUEIREDO, J. Armbrust. Lobotomia transorbitária. Resultados obtidos em 54 pacientes em hospital privado. Arquivos de Neuro-Psiquiatria, v. 14, n. 4, 1956.

26 MASIERO, 2003, op. cit., p. 571.

27 SCARCELLI, Ianni Regia; ALENCAR, Sandra Luzia de Souza. Saúde Mental e Saúde Coletiva: Intersetorialidade e Participação em Debate. Caderno Brasileiro de Saúde Mental, v. 1, n. 1, 2009 , p. 4.

${ }^{28}$ Essa interlocução pode ser vista em grande parte como contributo da atuação do Movimento da Luta Antimanicomial, ativo desde 1987, que proporcionou no âmbito das políticas públicas a aprovação da Lei de Reforma Psiquiátrica (no 10.216/2001).

29 BARRETTO, 1944, op. cit., 249.

${ }^{30}$ Idem. Nesta passagem, Barretto explicita seu agradecimento aos psiquiatras Edgard Pinto Cesar, Darcy de Mendonça Uchôa, Eduardo Guedes, Nilo Trindade e Silva, José Bottiglieri, Rachel Mendes e Mário Yahn por terem "enviado os doentes" para esta intervenção.
} 
sobre o advento da técnica, a qual Barretto define como "a última aquisição no campo da psicocirurgia e, também, a mais exata e controlável" 31 . Com propósitos semelhantes, ambos os trabalhos trazem uma devolutiva de experiências realizadas no Hospital de Juqueri, das quais é possível extrair - por meio de casuísticas e análises quantitativas expostas pelo próprio autor - os perfis nosológicos conduzidos para este tipo de procedimento e seu impacto na condição fisiológica e na socialização desses pacientes.

Ambas as publicações são compostas por descrições detalhadas das etapas seguidas do pré ao pós-operatório, nas quais Barretto especifica os medicamentos utilizados na assepsia e na anestesia (somente local); as características do leucótomo, a cânula de metal com a qual se realiza a trepanação; os locais exatos onde devem ser realizadas as incisões; e a forma correta de suturar o couro cabeludo. Manifestando seu acordo com a tese de L. Hofstatter, o autor acredita que a efetividade da lobotomia é nítida quando se realiza somente a secção dos quadrantes inferiores dos polos frontais, de forma tal que as áreas orbitárias desempenhariam o papel de "regulador das emoções"32. No que se refere à seleção dos pacientes submetidos à lobotomia, acredita que o encaminhamento não é determinado por seu estado geral e nem mesmo por sua faixa etária; segundo ele, "muitos doentes em mau estado geral melhoram sensivelmente com a intervenção"33, e houve casos de pacientes com mais de 60 anos que não tiveram quaisquer complicações secundárias após a cirurgia. Os perfis nosológicos dos 100 primeiros casos observados no Hospital de Juqueri - os quais foram supervisionados pelo psiquiatra Mário Yahn e operados, em parte (34 das intervenções), pelo Dr. Aloísio Mattos Pimenta - constituem em 93 diagnosticados com esquizofrenia, 3 com personalidades psicopáticas (episódios diversos), 3 com debilidade mental (episódio apático, confusional e crise hipomaníaca) e $1 \mathrm{com}$ psicose maniacodepressiva ${ }^{34}$. Os resultados imediatos descritos são a hipertermia (em média $38^{\circ} \mathrm{C}$ ), grandes edemas palpebrais e, com menos frequência, vômitos, cefaleia e perturbações no esfíncter; quanto aos efeitos psíquicos, observam-se a apatia e a perda de iniciativa. Na alusão aos resultados tardios apresentados no artigo de 1944, Barreto considera que 24 dos 100 pacientes foram influenciados positivamente pela intervenção, tendo 8 deles apresentado melhora e 16 remissão; dentre os demais casos, 75 permaneceram inalterados e um faleceu devido a uma "forte hemorragia acidental ao nível do lobo frontal" 35 . Por outro lado, a publicação de 1945 não conta com um registro descritivo ou mesmo quantitativo dos resultados posteriores.

Discorrendo sobre os resultados de outras 42 intervenções realizadas desde outubro de 1943, Barretto aponta que não foi registrada nenhuma morte ou quaisquer acidentes graves no ato cirúrgico e no pós-operatório. Com a prática de conversar com os doentes durante o processo, destaca que estes se mostram confusos a partir da secção das fibras tálamo-frontais, mas que os pacientes saem da mesa cirúrgica sem nem mesmo necessitarem da ajuda dos enfermeiros, apresentando sintomas semelhantes aos descritos no estudo anterior, aludidos como passageiros. A recuperação é rápida: "do terceiro dia em diante o paciente já se levanta e, no $5^{\circ}$ ou $6^{\circ}$ dia, são retirados os pensos", mas já nos primeiros dias deve ser iniciado o que chama de "reeducação psíquica"36. Apesar da ausência de incidentes, o autor não considera os resultados observados positivos como os referidos por Freeman e Watts, o que justifica como uma provável consequência do que chama de "péssimo material que pudemos utilizar, todo êle constituído de casos crônicos, considerados incuráveis, já submetidos a outros tratamentos psiquiátricos tais como insulina, cardiazol e eletrochoque e, mesmo, já operados pela técnica de Moniz, sem resultado

\footnotetext{
${ }^{31}$ BARRETTO, 1945, op. cit., 420.

32 Idem, p. 425.

33 Idem, p. 421.

34 BARRETTO, 1944, op. cit., p. 252.

35 Idem.

36 BARRETTO, 1945, op. cit., p. 425.
} 
algum. Acresce ainda o índice cultural nulo da maioria dos doentes e a dificuldade de reeducação no pós-operatório"37.

Fundamentada por uma retórica defensiva, a passagem destacada tem como objetivo claro a exposição de justificativas para o insucesso das intervenções. Em primeiro momento, a caracterização dos pacientes submetidos à lobotomia como péssimo material - justificado, nesse caso, por se tratarem de indivíduos diagnosticados com patologias mentais crônicas - sinaliza o caráter experimental dos procedimentos descritos nas publicações em questão. A perspectiva objetificante observada nessa passagem sugere que os fins visados pela intervenção residem primariamente na utilização dos pacientes como objeto de estudo; nesse sentido, a garantia dos efeitos positivos das psicocirurgias, bem como a salvaguarda dos que foram submetidos a elas, não se inseririam como prioridade da equipe de psiquiatras e cirurgiões que as conduziram. Da mesma forma, a alusão ao que chama de indice cultural nulo constitui-se como uma abrangente, porém vaga caracterização depreciativa dos pacientes - a qual, na concepção do autor, isentaria a equipe médica dos resultados negativos expostos. Justaposta a essa justificativa, a menção à dificuldade de reeducação psíquica, aludida como uma medida a ser tomada logo após a operação, reforça a ideia de que a propositiva do referido tratamento é a imposição de padrões comportamentais reconhecidos como inócuos, resignados ou normais.

A fim de legitimar a realização de mais de uma intervenção cirúrgica nos casos em que a lobotomia pré-frontal não proporciona melhorias no primeiro procedimento, Barreto expõe a casuística de Maria C., a quem descreve como uma mulher de 25 anos, branca, casada e brasileira. Internada com o diagnóstico de esquizofrenia hebefrênica em junho de 1943, foi submetida a trinta crises cardiazólicas até fevereiro do ano seguinte, as quais não influenciaram em seu estado. A paciente permaneceu "apática e de facies indiferente; às vezes, ria de maneira infantil e o pensamento não era ordenado segundo uma certa tensão psicológica originada num fim a ser atingido"38. Após a revisão de seu caso, propôs-se como novo tratamento a submissão ao coma insulínico - que, da mesma forma, manteve inalterada a "estrutura esquizofrênica". Apesar de ter recebido um prognóstico negativo, em 12 de maio de 1944 foi encaminhada para a leucotomia, a qual foi realizada por meio da técnica de Egas Moniz ${ }^{39}$. Mantida sua condição de apatia e desinteresse, suas "respostas sem colorido afetivo", o "riso fácil" e a expressão tola ${ }^{40}$, foi encaminhada para uma lobotomia pré-frontal, à qual foi submetida em 20 de outubro de 1944. Após um período pós-operatório considerado normal, começou a apresentar sensíveis melhoras, segundo o corpo médico, voltando a auxiliar nos serviços da enfermaria e interessando-se pela sua alta. Após 4 meses, o marido pedia alta definitiva, posto que a julgava totalmente normal, informando que ao chegar em casa logo se mostrou alegre e disposta, passando a ocupar-se dos afazeres com grande proficiência". O primeiro ponto observado na casuística em questão é a descrição do diagnóstico. Conceituadas pelo psiquiatra Maurício Levy Junior, as hebefrenias são caracterizadas pela "predominância dos sintomas no setor afetivo" com "sinais abundantes de liberação afetiva - risos, cantos, exageros, caretas, gestos múltiplos - tudo, porém, executado de

${ }^{37} \mathrm{Idem}$

38 Idem, p. 426.

${ }^{39}$ Como aludido por Barreto, "a leucotomia visa atingir as fibras de conexões da porção anterior dos lobos frontais, tendo como objetivo interromper os arranjos celuloconectivos estabelecidos nos cérebros dos alienados. Para obter este resultado, é preciso atingir o centro oval, na altura do lobo frontal e destruir uma parte limitada deste centro, lugar por onde passam as fibras de conexão das células do córtex. Esta destruição poderá ser feita por um líquido que ataca o tecido nervoso (álcool absoluto) ou cirurgicamente, pelo leucótomo" (BARRETTO, 1944, op. cit., p. 249).

40 BARRETTO, 1945, op. cit., p. 426.

${ }^{41}$ JUNIOR, Maurício Levy. Contribuição para o estudo das psicoses atípicas: esquizofrenias com manifestações maníacas. Arquivos de Neuro-Psiquiatria, São Paulo, v. 8, n. 1, 1950, p. 65. 
maneira inadequada, saltuária, sem nexo, sem conteúdo lógico"42, fator este que possibilitaria o a diferenciação do diagnóstico da mania. No caso da esquizofrenia hebefrênica, o autor destaca que os limites das hebefrenias foi muito estendido, de forma tal que todas as formas clínicas de esquizofrenias que não estivessem circunscritas nos tipos clássicos fossem inseridas nessa categoria, "principalmente as esquizofrenias atípicas, com manifestações maníacas, depressivas, histéricas, compulsivas, etc. Entre as diversas formas de esquizofrenia, é, portanto, a hebefrênica a que melhor se presta à possibilidade de confusões com a mania" ${ }^{43}$. Somada à forma como as reações da paciente são descritas - sua apatia, os risos infantis e a desordem de seus pensamentos, a que Barretto pode ter se referido pensando na premeditação -, essa caracterização sugere a possibilidade de que a patologização de suas condições seja questionada. Patologização essa que, a princípio, somente se justifica pela existência de padrões de normalidade pré-definidos; os quais, por sua vez, podem estar direta ou indiretamente associados ao perfil comportamental idealizado para uma boa esposa e dona-de-casa, no caso em questão. Ao fim de sucessivos tratamentos frustrados, incluindo uma leucotomia realizada pelo método de Egas Moniz, o objetivo foi atingido: depois de ser submetida a uma lobotomia pré-frontal, passou a auxiliar nas atividades da enfermaria e interessou-se por sua alta, a qual foi concedida meses depois, após seu marido perceber a sua "sensível melhora" 44 . Ao chegar em casa, a sua normalidade novamente foi constatada, pois logo mostrou-se disposta a ocupar-se dos afazeres domésticos.

Outro caso descrito por Barretto é o de Maria Piedade R., descrita como uma mulher de 24 anos, branca, brasileira e solteira. Apesar de ter manifestado sintomas quatro anos antes, somente foi internada em 22 de maio de 1943. Seu diagnóstico coincide com o da casuística anterior: "síndrome esquizofrênica, forma hebefrênica"45. Nos três primeiros meses de tratamento, foi encaminhada à "terapêutica pelo eletrochoque" 46 , mas as vinte crises às quais foi submetida não surtiram resultados. Após a revisão de seu tratamento pelo psiquiatra Mário Yahn, direcionaram-na para a insulinoterapia, período no qual foi induzida a quarenta comas - que também não influenciaram em sua condição. Em 3 de dezembro de 1943, foi realizada a leucotomia, aludida como uma "última tentativa terapêutica" 47 . Semanas depois de constatarem a não-influência em seu estado mental, os efeitos começaram a ser percebidos: em janeiro de 1944 começaram a aparecer o que o autor reconhece como as primeiras melhoras, e em 23 de maio foi constatada a remissão completa. "Deixou o hospital em 11 de abril de 1944, demonstrando reconhecimento pelo que lhe foi feito, estando com ótima modulação afetiva, com pleno conhecimento do estado mórbido pregresso" 48 . Diferindo do anterior, o relato em questão foi desenvolvido de maneira mais sucinta, sem que houvesse a intenção de expor os sintomas da paciente, os quais são sugeridos apenas ao final, quando Barretto refere-se à sua recuperação. Como sinaliza o autor, a efetividade do procedimento pôde ser constatada pela capacidade de modulação afetiva da paciente, que antes apresentava-se em estado mórbido. Essa descrição pode sugerir que, nesse caso, espera-se que um indivíduo como Maria Piedade - uma mulher solteira de 24 anos - seja capaz de manter a sua estabilidade emocional, que, assim como o anterior, é um padrão de normalidade impositivo e subjetivo. Outro aspecto passível de abordagem é a relação de poder existente entre médicos e pacientes, a qual é naturalmente amplificada pela posição de vulnerabilidade nas quais os aludidos como doentes são mantidos em um hospital psiquiátrico que nada mais é do que um espaço de exclusão. Nesse sentido, pode-se considerar o reconheci-

\footnotetext{
42 Idem, p. 66.

43 Idem.

${ }^{44}$ BARRETTO, 1945, op. cit., p. 426.

${ }^{45}$ BARRETTO, 1944, op. cit., p. 253.

${ }^{46}$ Idem.

47 Idem.

48 Idem.
} 
mento da eficácia do tratamento por parte dos próprios pacientes como uma tentativa, consciente ou não, de romper os vínculos com os psiquiatras e a com própria instituição nas quais foram submetidos a essas terapias invasivas, agressivas ou letargiantes.

\section{A lobotomia no âmbito de uma instituição privada: Instituto Paulista}

No ano de 1949, Paulino W. Longo, A. Mattos Pimenta e Joy Arruda ${ }^{49}$ publicaram um estudo com o objetivo de expor os resultados obtidos em tratamentos com a lobotomia préfrontal no Serviço de Neuro-Psiquiatria do Instituto Paulista. Enunciado por um breve histórico do advento e disseminação da técnica, o artigo contempla uma abordagem diversa da observada nas publicações de Barretto: enquanto o autor tenciona promover uma explanação do método utilizado, assumindo um tom distanciado dos pacientes submetidos à intervenção e expondo uma breve análise quantitativa dos resultados, o trabalho produzido pelo Instituto Paulista é voltado majoritariamente para a análise dos resultados à luz do estudo de casos. Esse objetivo é justificado pelo fato de que o "material humano dos hospitais psiquiátricos públicos muito deixa a desejar em relação aos dois primeiros aspectos de seleção aconselhados por Freeman" 50 , descritos como a seleção dos pacientes com base na tensão emocional evidente e o interesse dos familiares na reabilitação pós-operatória ${ }^{51}$. A ideia dos autores é, portanto, selecionar um espaço amostral em que os indivíduos submetidos à lobotomia pré-frontal não sejam diagnosticados com psicopatologias em estado de cronicidade avançada e, ao mesmo tempo, possam contar com o suporte da família ${ }^{52}$ - que pode tornar-se um contributo por aspectos práticos, como o financeiro, ou pelo aspecto emocional.

Os perfis nosológicos selecionados para a execução da lobotomia pré-frontal compreendem 14 pacientes com o diagnóstico de esquizofrenia, sendo 1 da forma simples, 2 da demencial, 2 da catatônica e 7 da paranóide; 1 diagnosticado com neurose obsessiva; 2 com síndrome depressiva ansiosa; 2 com psicose maniaco-depressiva (mania); 1 com sindrome confusional crônica; e $1 \mathrm{com}$ debilidade mental, caracterizada como surto psicótic ${ }^{53}$. Após a realização dos procedimentos, não foi constatado nenhum óbito e nenhum agravamento da condição dos pacientes; contudo, 7 pacientes não apresentaram quaisquer tipos de melhora; 5 foram descritos como pouco melhorados clinicamente; 3 obtiveram melhoras consideráveis; 6 foram considerados como curados devido ao "desaparecimento dos sintomas psicóticos ou neuróticos" 54 , dentre os quais foram contabilizados dois indivíduos que, apesar da "perfeita reintegração nos ambientes social, familiar e de trabalho" 55 , haviam sido operados recentemente e continuavam em observação; 7 ainda permaneciam hospitalizados; 6 já haviam recebido alta, mas ainda não eram capazes de trabalhar; e 8 haviam não

49 Na publicação em questão, Paulino W. Longo é descrito como Diretor-clínico do Serviço de Psiquiatria do Instituto Paulista e catedrático de Neurologia na Escola Paulista de Medicina; A. Mattos Pimenta como neurocirurgião do Hospital de Juqueri; e Joy Arruda como psiquiatra do Serviço de Neuro-Psiquiatria do Instituto Paulista e da Secção de Higiene Mental Escolar.

${ }^{50}$ LONGO, 1949, op. cit., p. 131.

$51 \mathrm{O}$ primeiro aspecto destacado por Freeman está vinculado à "elevada percentagem de curas nas séries de pacientes operados em seu primeiro ano de hospitalização" (LONGO, 1949, op. cit., p. 131). Já o segundo é justificado pelo fato de que, quando a família coopera com o processo de recuperação, "muito pode ser feito, mesmo nos casos mais crônicos de esquizofrenia e depressão agitada" (idem), e o terceiro refere-se "à tática cirúrgica; com os aperfeiçoamentos introduzidos considera Freeman que, em cada operação, deve-se decidir onde e como fazer as incisões: em casos crônicos e graves com deterioração, para obter bons resultados, as incisões devem ser feitas 6 a $10 \mathrm{~mm}$. Atrás do plano da espinha esfenoidal" (idem).

52 Idem.

${ }^{53}$ Idem, p. 136.

54 Idem.

${ }^{55} \mathrm{Idem}$. 
só recebido alta, como exerciam "atividade útil (parcial ou total)" deradas complicações graves, observaram crises convulsivas frustras no dia subsequente à psicocirurgia em dois casos. Além desses, dois dos pacientes submetidos à intervenção sofriam de epilepsia, o que levou um deles a apresentar crises epilepticas típicas e outro a sofrer convulsões pregressas mostrando disritmia cerebrab77. Aludindo às "modificações da personalidade", os autores promovem uma análise otimista dos resultados, a qual revela aspectos importantes do que se costuma esperar do tratamento:

(...) logo no dia seguinte ao ato cirúrgico, o paciente libertase da ansiedade, dos pensamentos obsessivos, da ambivalência e dos sentimentos de inferioridade. Torna-se consciente de si próprio e é capaz de voltar aos seus interesses externos. Responde adequadamente aos estímulos, porém mostra-se eufórico, ligeiramente superficial e infantil. Não mostra aspirações elevadas, projetando-se pouco no futuro. Sua ambição e reduzida e satisfaz-se com a vida diária. Torna-se amável, bondoso, um tanto indiferente à opinião alheia. Perde a impulsividade e agressividade. ${ }^{58}$

Nota-se, portanto, que os objetivos gerais da psicocirurgia estão relacionados ao potencial de viabilizar um relacionamento "satisfatório" do doente com o mundo externo. Idealmente, isso deve ocorrer sem que este desenvolva grandes ambições, preocupando-se somente com suas tarefas cotidianas. Dentre os atributos comportamentais, observa-se a expectativa de que os indivíduos não ajam de forma impulsiva e agressiva, o que sugere a valorização da previsibilidade e resignação em suas posturas.

Com base nos índices apresentados por Freeman e Watts, espera-se que por volta de um terço dos pacientes sejam curados, outro terço apresente melhoras em suas condições e os demais não sejam influenciados pela psicocirurgia. Tais dados estão em consonância com os relatórios de várias clínicas em todo o mundo ${ }^{59} \mathrm{e}$ aproximam-se dos dados expostos ao final do estudo, pela perspectiva dos autores. Dentre os 21 pacientes operados, 6 foram considerados curados, 9 foram "beneficiados"60 e 6 não apresentaram alterações no quadro clínico. Apesar disso, a equipe responsável pelo estudo considera que a utilização da lobotomia como tratamento cirúrgico de algumas formas de doenças mentais é "plenamente justificada" ${ }^{61}$. A lobotomia seria um método terapêutico sobretudo nos casos de ansiedade crônica e esquizofrenia paranoide, com base nos resultados obtidos, mas os autores destacam a importância de que a intervenção seja realizada precocemente. “(...) quanto maior a tensão emocional e a produtividade psicopatológica e menor o rebaixamento intelectual, mais brilhantes serão os resultados" ${ }^{\prime 2}$. A fim de expor panoramicamente a sintomatologia, o diagnóstico, a duração da doença, os resultados obtidos e a evolução dos casos, os autores apresentam relatos dos 21 pacientes analisados. Em muitos deles, é notório que os sintomas fundantes das condições nosológicas são subjetivos e/ou atrelados a padrões comportamentais reconhecidos cultural, social e economicamente como negativos ou contraproducentes, em certos aspectos. Destaco abaixo alguns exemplos que se encaixam nesta categoria:

\footnotetext{
56 Idem.

${ }^{57}$ Idem, p. 137.

58 Idem.

${ }^{59}$ Idem, p. 127.

${ }^{60}$ Idem, p. 139.

${ }^{61}$ Idem, p. 138.

${ }^{6}$ Idem.
} 
Caso 1: Lidia L. H., síria ${ }^{63}, 42$ anos, branca, casada. Súmula clínica: Excitação psicomotora permanente. Desconexão psíquica, indocilidade, atitudes de pavor, indiferença on agressividade. Rebaixamento global intelectual. Não influenciada pelos tratamentos de choque. Doente há mais de 10 anos. Diagnóstico: Esquizofrenia crônica, estado demencial. Lobotomia: Procedida em 15 de agosto de 1945. Resultado imediato: Estado mental não influenciado. Retirada do hospital em 2 de outubro de 1945. Resultado ulterior: Permanece no lar, apresentando melhoras que tornam compatível sua vida na família, sem exercer atividade prática útil. Pouco melhorada, continuava em casa em maio de 1948.

Caso 2: Francisco S., brasileiro, 40 anos, solteiro, médico. Súmula clínica: Doente há 14 anos. Sindrome delirante, alucinatória, persecutória e polimorfa; desagregação ideativa, inafetividade, irritabilidade psicomotora; risos, gestos e atitudes estereotipadas; incapaz de atividade coordenada e útil; surtos de agitação, agressividade e destrutibilidade. Submetido a todos os tratamentos de choque, sem resultado. Diagnóstico: Esquizofrenia paranoide, em estado crônico. Lobotomia: Primeira operação em dezembro de 1946, seguida de convulsões predominantes à direita e estado comatoso durando cerca de três dias. Resultado imediato: Boas melhoras mentais e físicas, com desaparecimento dos sintomas psicóticos, durante 5 meses. Resultado ulterior: Reincidência da síndrome alucinatória de influência estranha. Comportamento calmo. Falta de consciência do estado mórbido. Vida pragmática fácil e rudimentar sem sequelas neurológicas. Pouco melhorado. Continua no hospital em maio de 1948. (idem, ibidem: 132, grifo nosso)

Caso 15: A. Barbato, italiano, solteiro, 20 anos. Súmula clínica: Doente desde outubro de 1943. Excitação psicomotora intensa. Canta, chora, ri, enfeita-se extravagantemente, agressivo, chafurda-se em espurcícia, desconexão ideativa, insônia. Diagnóstico: Excitação maníaca. Psicose maníaco-depressiva. Surto anterior em 1935, tipo mania. Lobotomia: Em 20 de dezembro de 1944. Resultado imediato: Me-

${ }^{63}$ Dos 20 casos que possuem a caracterização da nacionalidade, observa-se que 7 são estrangeiros. Tratamse dos casos 1, 3, 5, 6, 12, 14, 15, correspondentes à Lídia L. H., síria; Olga D., russa; Eva T., inglesa; Francisco R. M. P., espanhol; S. Nutes, israelita; F. B. Barata, americana; e A. Barbato, italiano (LONGO, 1949, op. cit., pp. 132-134). Sobre esta questão, Pacheco e Silva alude que "o número de psicopatas estrangeiros é muito maior, proporcionalmente, ao de nacionais, que demonstra a necessidade de se estabelecerem medidas rigorosas, não só visando a seleção racial como a seleção individual dos imigrantes. A nossa experiência demonstra ser a raça negra menos sujeita à paralisia geral e mais exposta ao alcoolismo e às psicoses alucinatórias. Os casos de paralisia geral são também mais raros entre os indivíduos da raça amarela, que por sua vez são acometidos, com maior frequência, pelas formas esquizofrênicas. Muitos autores se referem à frequência das psicopatias entre os israelitas. A nossa observação confirma esse modo de pensar, cumprindo entretanto ponderar não ser possível consignar-se se tal ocorre em virtude de uma miopragia nervosa peculiar à raça ou se tal se deve a outros fatores oriundos da perseguição contra eles movida e que recrudesceu nestes últimos anos sob o advento do nazismo e do fascismo, lançando a desolação e a morte a milhões de pessoas, forçando os sobreviventes a emigrarem e a recomeçarem a vida em circunstâncias nem sempre favoráveis, após terem padecido profundos abalos emocionais e sofrimentos físicos inenarráveis" (PACHECO E SILVA, Antonio Carlos. Psiquiatria Clínica e Forense. São Paulo: Renascença, 1951, pp. 35-36). 
lhoras imediatas e progressivas. Acalmia, interesse prático e atividades simples. Ideação e comportamento normais. Resultado ulterior: Acentuação das melhoras. Reintegração satisfatória no ambiente familiar, social e no trabalho. Considerado curado em maio de $1948 .{ }^{64}$

Assim como a subjetividade e a imposição de padrões projetada na sintomatologia, a questão das atividades práticas também há de ser pontuada. Antes da intervenção, a ocupação é utilizada como parâmetro para sinalizar a gravidade do quadro nosológico ${ }^{65}$; no pós-operatório, para confirmar o sucesso ou justificar o insucesso da lobotomia ${ }^{66}$. Partindo de uma perspectiva estrutural, pode se considerar que essa abordagem utilitária está alinhada aos padrões comportamentais esperados pelos indivíduos em uma sociedade organizada economicamente pela lógica capitalista, a qual fundamenta pela dessubjetivação do indivíduo com o intento de validar a mercantilização deste como força de trabalho. No contexto em questão, esse movimento consiste no reconhecimento da normalidade por meio da capacidade demonstrada de se cumprir com as demandas sistêmicas - que, em aspectos práticos, transformam-se em exigências dos empregadores (ou potenciais empregadores) e familiares - de responsabilizar-se por atividades práticas condizentes com o que se espera de seu papel social, cuja definição pode ser condicionada por fatores como o gênero, classe e raça. Nota-se que a atuação no mercado de trabalho é destacada somente na casuística de pacientes do sexo masculino; o papel de gênero usualmente designado aos homens na esfera privada corresponde à função de provedores do sustento e segurança. Também sustentado por arquétipos patriarcais, um dos parâmetros notadamente adotados para

${ }^{64}$ LONGO, 1949, op. cit., p. 134, grifo nosso.

${ }^{65} \mathrm{Na}$ súmula clínica dos $4^{\circ}$ e $21^{\circ}$ casos analisados, correspondentes à Dorah V. B. (descrita como branca, brasileira, solteira, 29 anos) e Edith P. (branca, brasileira, solteira, 22 anos), os autores destacam a "atividade descoordenada" (idem, p. 132) como um dos sintomas que caracterizam a psicopatologia das pacientes. De forma semelhante, nos casos 5, 7, 9, 11, 16, 18 e 20, que se referem, respectivamente, à Eva T. (descrita como inglesa, casada, 42 anos), W. M'onaco (brasileiro, branco, solteiro, estudante, 25 anos), Silvio E. L (brasileiro, branco, solteiro, industrial, 36 anos), Marcio M. (branco, brasileiro, solteiro, estudante, 25 anos), R. Sant'Anna (brasileiro, solteiro, 24 anos), Maria C. D. (branca, brasileira, casada, 40 anos), Delover V. (o relato em questão não possui a descrição do perfil), os autores aludem à carência ou falta de atividade prática (idem, pp. 132-134) e inatividade (idem, p. 135).

${ }^{66}$ Nas ocasiões em que a psicocirurgia não foi satisfatoriamente efetiva, as consequências que referenciam à incapacidade de realizar atividades práticas podem ser observadas nos casos 1, onde a paciente Lídia L. H. (síria, branca, casada, 42 anos) permanece no lar "sem exercer atividade prática útil" (idem, p. 132), assim como no caso 4, em que Dorah V. B (brasileira, branca, solteira, 29 anos) foi "internada no Sanatório Pinel sem atividade prática" (idem, ibidem), e no 14, em que F. B. Barata (americana, casada, 47 anos) recebeu alta do hospital, mas permanece "sem trabalhar e sob enfermagem" (idem, p. 134). Os casos 2, 6, 7, 11, 15, 16 não apresentaram melhoras significativas, e por isso exercem atividades simples e/ou "rudimentares" (idem, pp. 132-134) - descrição feita nos relatos correspondentes, respectivamente, à Francisco S. (brasileiro, solteiro, médico, 40 anos), Francisco R. M. P. (espanhol, casado, operário, 53 anos), W. M'onaco (brasileiro, branco, solteiro, estudante, 25 anos), Marcio M. (branco, brasileiro, solteiro, estudante, 25 anos), A. Barbato (italiano, solteiro, 20 anos), R. Sant'Anna (brasileiro, solteiro, 24 anos). Por outro lado, no âmbito dos resultados considerados positivos, encaixam-se os casos 8, 10, 12, 13, 18 e 21: A. A. Teles (brasileiro, casado, advogado, 30 anos) foi "reintegrado nas funções de seu cargo público" (idem, p. 133); Enio R. D. S. (branco, brasileiro, solteiro, médico, 29 anos) voltou às suas funções em "trabalho médico de rotina" (idem); S. Nutes (branca, israelita, casada, 41 anos) voltou a se interessar nas "atividades práticas do lar" (idem, p. 134); S. V. (brasileiro, branco, advogado, casado, 60 anos) tornou-se "capaz de trabalhar" (idem); Maria C. D. (branca, brasileira, casada, 40 anos) foi "reintegrada na vida familiar, social e nos afazeres domésticos" (idem, p. 135); Edith P. (branca, brasileira, solteira, 22 anos) voltou a dedicar-se aos "afazeres domésticos" (idem). 
reconhecer ou não a normalidade das mulheres é o fato de terem ou não capacidade e disposição para dedicarem-se às tarefas domésticas ${ }^{67}$.

\section{Conclusões}

A justaposição das análises correspondentes a instituições inseridas na ordem pública e privada possibilita a percepção de especificidades possivelmente atreladas aos aspectos dos diferentes espaços. A cobrança pelo atendimento prestado fundamenta a restrição do público assistido pelo Instituto Paulista, definido pelo recorte classista e racial; diferenciação essa que contribui com a dissonância dos métodos adotados pelos referidos hospitais. Com o tratamento custeado pelo estado, os pacientes do Hospital Juqueri ficam sujeitos a possíveis défices orçamentários (sejam eles ocasionados por crises econômicas e/ou por políticas de contenção de gastos), cenário que constantemente culmina na precarização dos serviços públicos. O comentário de Carlos Barretto acerca dos impactos financeiros potencialmente propiciados pela massificação do uso da lobotomia pré-frontal sugere, em primeiro momento, que o Hospital Juqueri está inserido neste contexto e coordenado sob estas condições. Por uma perspectiva mais ampla, também pode-se reconhecer como a transposição do olhar de um profissional da saúde para uma questão do âmbito das políticas públicas, voltada especificamente para o intento de reduzir os gastos com pacientes diagnosticados com psicopatologias. Segundo o autor,

A intervenção poderá suprimir o sofrimento íntimo dos ansiosos e melancólicos, diminuir a agitação psicomotora, diminuir certos complexos psíquicos, contribuindo, pois, para diminuir o número de doentes crônicos nos hospitais psiquiátricos. É fácil compreender que, sob o ponto de vista econômico, este método é mais vantajoso que qualquer outro tratamento, tanto pelo baixo custo da intervenção como pela rapidez com que surgem alguns dos resultados terapêuticos. ${ }^{68}$

Aliada aos rápidos resultados, a possibilidade de economia com a redução de internos em hospitais psiquiátricos e com os recursos utilizados no tratamento em si é evocada, por esse ponto de vista, como um argumento favorável à disseminação da prática da lobotomia pré-frontal em instituições psiquiátricas públicas. Nessa lógica é possível reconhecer o pressuposto de que os resultados obtidos são suficientemente favoráveis para legitimar a adoção desta psicocirurgia como método para atenuar os sintomas ou obter a cura dos doentes; percepção que, contudo, não se justifica pelos resultados vagamente apresentados nas publicações de Barretto. Como aludido pelo próprio autor, o fato de as intervenções terem sido realizadas em doentes com estado de cronicidade avançada - que, caracterizados por ele como "péssimo material”'69, já haviam sido submetidos a outras técnicas, como a insulinoterapia, eletrochoque e choques convulsivos induzidos por cardiazol - dificultou a obtenção dos "resultados brilhantes"70 anunciados por Freeman e Watts. Esse insucesso também é associado a particularidades atribuídas aos pacientes do Hospital Juqueri que, no ponto de vista do autor, possuem em maioria um "índice

\footnotetext{
${ }^{67}$ Idem, pp. 132-135.

68 BARRETTO, 1944, op. cit., p. 251.

${ }^{69}$ BARRETTO, 1945, op. cit., p. 425.

${ }^{70}$ Idem.
} 
cultural nulo"’11, o que dificulta o processo de reeducação. É possível que esse discurso se sustente pela construção de arquétipos discriminatórios pautada por fatores que trespassam a ordem do poder aquisitivo, como o capital social $^{2}$ e cultural $^{3}$, que, em suma, demarcam a diferenciação do público atendido em hospitais públicos e privados. Esse mesmo posicionamento pode ser observado no artigo desenvolvido por Paulino W. Longo, Mattos Pimenta e Joy Arruda, onde os autores referenciam aos resultados clínicos de outra série de procedimentos realizada pelo psiquiatra Mário Yahn, o qual obteve 14\% de remissões, $6 \%$ de melhoria e 1\% de incidência letal - dados considerados negativos, na opinião deles, provavelmente "em virtude da qualidade do material humano dos hospitais psiquiátricos públicos, já muito deteriorado pela longa duração da moléstia" "74. Os esforços para contrastar esse cenário com o do hospital particular em questão, o qual possui "pacientes cujas famílias cooperam e cujo estado de cronicidade da doença ainda não é muito avançado"75, revela a intenção de, não obstante o fracasso dos procedimentos realizados anteriormente, legitimar uma nova série de aplicações da lobotomia pré-frontal. Tal motivação se fundamenta pela ideia de que os resultados observados na literatura melhoram conforme se distancia do advento dos procedimentos, o que pode não ter ocorrido devido aos aperfeiçoamentos técnicos, mas à seleção do perfil dos pacientes. $\mathrm{O}$ balanço das intervenções realizadas no Serviço de Neuro-Psiquiatria do Instituto Paulista consistiu em 28,5\% dos pacientes considerados curados; $43 \%$ beneficiados e $28,5 \%$ não-influenciados, o qual os autores consideraram semelhante ao que Freeman e Watts prospectam em seus estudos.

Positivos ou não, os resultados apresentados nas publicações analisadas não se constituem como pareceres objetivos, imparciais e irrefutáveis das condições dos pacientes que foram submetidos à lobotomia pré-frontal - o reconhecimento da validade desses dados quantitativos demandaria, em primeiro momento, a elucidação do que os autores compreendem como melhoria ou cura desses indivíduos. Aludindo às críticas sobre os "possíveis prejuízos intelectuais nos lobotomizados"76, a equipe de Paulino W. Longo justifica que "muitas das alterações da personalidade verificadas após a operação dependem do tipo de personalidade pré-psicótica do indivíduo, não sendo diretamente imputáveis à operação" "77; logo, os autores compreendem que alguns sinais de deficiência do lobo frontal (e.g. diminuição da inibição, dificuldade de síntese e iniciativa, preguiça) revelam-se como manifestações compensatórias da sintomatologia psicótica anterior. A articulação deste argumento com as casuísticas apresentadas sugere, em termos gerais, que os atributos associados à condição de um paciente curado ou beneficiado são a acalmia, a capacidade de exercer atividade útil e integração à vida familiar e social. Tencionava-se, portanto, que se mantivesse o controle sobre o comportamento dos indivíduos diagnosticados com psicopatologias, preferencialmente possibilitando que estes exercessem seu respectivo papel social noção essa que está alinhada com o discurso imbuído na frase usualmente atribuída a Freeman e Watts: "It is better for him to have a simplified intellect capable of elementary acts than an intellect where there reigns disorder of subtle synthesis. Society can accommodate itself to the most humble laborer, but it justifiably distrusts the mad thinker"78. Tal propósito remete, de forma geral, ao conceito de normalização evocado por Georges Canguilhem em seu $O$ normal e o patológico, no qual alude que

\footnotetext{
${ }^{71}$ Idem.

${ }^{72}$ BOURDIEU, Pierre. The forms of capital, In: J. G. Richardson (org.). Handbook of Theory and Research for the Sociology of Education, Nova Iorque: Greenwood, 1985, pp. 241-258.

73 BOURDIEU, Pierre. Escritos de Educação. Petrópolis: Vozes, 1999.

${ }^{74}$ LONGO, 1949, op. cit., p. 130.

${ }^{75}$ Idem, p. 131.

${ }^{76}$ Idem, p. 129.

77 Idem.

${ }^{78}$ BYARD, 2017, op. cit., pp. 4-5.
} 
(...) a normalização dos meios técnicos da educação, da saúde, do transporte de pessoas e de mercadorias é a expressão de exigências coletivas cujo conjunto define, em determinada sociedade histórica, seu modo de relacionar sua estrutura, ou talvez suas estruturas, com aquilo que ela considera como sendo seu bem particular, mesmo que não haja uma tomada de consciência por parte dos indivíduos. ${ }^{79}$

Nesse sentido, a caracterização do que se compreende por normal se constitui por meio da referência a uma norma imanente, pois todo valor só pode ser obtido em função - nesse caso, oposição - de outro valor, o que fundamenta a depreciação do anti-exemplo ao mesmo tempo em que possibilita a inversão dos termos que caracterizam a relação polarizada entre os ditos normal e anormal. Por não determinar diretamente os seus efeitos, uma norma não se constitui como uma imposição imponderável, como ocorre no caso das leis naturais, e sim como uma proposição: da mesma forma que se concebe como uma possibilidade de referência e regulação, ela também sinaliza outra possibilidade diametralmente inversa. Denota-se, por esses aspectos, que o conceito de normal não é estático, e tampouco pacífico; ele se compreende por seu caráter dinâmico e polêmico ${ }^{80}$. Trata-se de um estado passível de alterar-se conforme o contexto, o qual se estabelece de maneira controversa, sujeita a debate. Dentro de cenários nos quais se impele aos indivíduos a necessidade de se condicionar a papéis sociais, é possível reconhecer que o padrão de normalidade está comumente associado à capacidade de resignar-se às suas respectivas funções. O cumprimento de tais atribuições seria afetado ou mesmo impedido em casos com as sintomatologias supramencionadas: logo, o estado apático e letárgico obtido após a execução da lobotomia pré-frontal pode ser reconhecido como uma solução viável para garantir a normalização desses pacientes.

Caracterizados por seu estado letárgico, plácido, dócil, desinteressado, infantilizado, entorpecido, apático, dependente e despropositado ${ }^{81}$, os pacientes lobotomizados tiveram seu perfil comportamental moldado para que se encaixassem em padrões compatíveis com o que se espera de um indivíduo normal. A adoção da lobotomia como tratamento corresponde a um método truculento de se impor essa lógica patologizante, o qual visa lograr a normalização ${ }^{82}$ dos pacientes de forma abrupta e pouco dispendiosa no que se refere à estrutura necessária para a condução do procedimento. Tais propósitos estão alinhados com o papel cumprido por artigos de difusão como os analisados neste estudo, que têm em vista promover a lobotomia pré-frontal por meio da exposição da técnica e dos resultados obtidos com a sua aplicação nos diferentes espaços evocados - o Hospital do Juqueri e o Serviço de Neuro-Psiquiatria do Instituto Paulista. Presente nas esferas pública e privada, o viés imediatista que norteia essa metodologia pode ser reconhecido como representativo ao denotarmos o seu alinhamento com a racionalidade da Medicina ocidental, cujos preceitos permaneceram - e permanecem - visíveis na Psiquiatria mesmo depois que a técnica da lobotomia pré-frontal caiu em desuso, com a utilização de tratamentos similarmente letargiantes e agressivos como muitos psicofármacos e as internações compulsórias. Partindo de uma via propositiva, destaca-se a validade da aplicação dos pressupostos da Saúde Coletiva ${ }^{83}$ nas práticas psiquiátricas, de forma que se contextualizem as condições nosológicas dos pacientes por

${ }^{79}$ CANGUILHEM, Georges. O normal e o patológico. Rio de Janeiro: Forense Universitária, 2009, p. 108.

${ }^{80}$ Idem, p. 109.

${ }^{81}$ BYARD, 2017, op. cit., p. 5.

82 CANGUILHEM, 2009, op. cit.

83 NUNES, Everardo Duarte. Saúde coletiva: história de uma idéia e de um conceito. Saúde e Sociedade, São Paulo, v. 3, n. 2, 1994; FILHO, Naomar de Almeida. Transdisciplinaridade e saúde coletiva. Ciência \& 
seus aspectos sociais, históricos e culturais - movimento que pode ser alicerçado pelas bases teóricas da Psicologia Sócio-Histórica ${ }^{84}$, pautada pelo estudo do psiquismo e da subjetividade em sua abordagem totalizante.

Saúde Coletiva, v. 2, n. 1/2, 1997; BRITO, Jussara. Trabalho e saúde coletiva: o ponto de vista da atividade e das relações de gênero, Ciência \& Saúde Coletiva, Rio de Janeiro, v. 10, n. 4, 2005.

${ }^{84}$ BOCK, Ana M. Bahia; GONÇALVES, M. Graça M.; FURTADO, Odair (org.). Psicologia Sócio-Histórica: uma perspectiva crítica em Psicologia. São Paulo: Cortez, 2015. 